frequented. At present they are only open on three days of the week, and even then only in the afternoon, so that if a lecture is held in the afternoon (as happened in my year) what time is left for reaching Chelsea?

I am, Sir, your obedient servant,

King's College, London, Sept. 1860.

H. Stavifix Gale.

\section{CERTIFICATES IN CASES OF LUNACY.} To the Editor of THE LANCET.

SIR,-The leading article in your journal of last week on the conduct of Mr. Jefferys proceeds on the assumption that he had signed a certificate of insanity according to the form re quired by the statute, without having previously visited the patient. You will probably be surprised to learn that he has not signed such a certificate of insanity; that he has not cer tified that be has personally visited; and that he has not in any way infringed the statute. The following is a copy of the form actually signed:-

$$
\text { "St. Paneras, Middlesex, }
$$

o'clock .M.

"Please admit to the infirmary this patient suffering from mental excitement, and incapable of being attended at his residence in consequence of requiring restraint; said to be dangerous. (Signed)

W. E. JEFFERYS.

"To the Master of St. Pancras Workhouse."

The parish medical order, issued from the overseers' office withont a previous visit to the patient as required by the Poor law Act, was taken to Mr. Jefferys by two neighbours of the patient on the evening of the day of issue. Mr. Jefferys was leaving his house to attend at a confinement. He explained to the parties the urgency of the call, which prevented his visiting immediately; but yielding, no doubt incautiously, to their pressing representations of the danger to which their children were exposed from the violence of the individual, backed by a strong message from his medical attendant, he signed the order for his admission to the infirmary.

This order confers no authority on any person to remove the patient; it is neither more nor less than what it professes to be-an order of admission to the infirmary, equivalent to a governor's order of admission to a general hospital. The power to remove remained, unaffected by this order, where it is left by the statute-with the relatives or connexions of the patient, who might, without infringing the statute, have removed him to the workhouse, where be might have been admitted under this order; or they might, as they have chosen to do, remove him elsewhere, this order notwithstanding. In fact, no action has been taken under this order, because it conferred no power of acting till the patient's arrival at the gate of the workhouse. If on his admission it had there been found necessary to place him under restraint, the statute allows a certain number of days for signing the legal certificates in due form.

Mr. Jefferys may have infringed the regulations of the vestry by signing an order of admission to their infirmary without previously visiting the patient, but this appears to be the full extent of his offence. "The liberty of the subject has not been invaded;" there was no risk of " incarceration contrary to the statute;" nor the remotest probability of "involving the parish in endless litigation;" all of which illusions floated in the mirage raised before the eyes of the imagination of the smaller half of the directors of St. Pancras; for, to the credit of the board be it said, a milder vote of censure was re jected only by the double vote of the senior churchwarden. To me, a ratepayer of that parish, professionally familiar with the medico-legal bearings of the matter, the reprimand administered appears anything but lenient; while the unauthorized, exaggerating comments of the churchwarden, as reported, have rendered the censure, to quote his own words, "a farce."

Your well-known impartiality will, I confidently trust, in sure the insertion of this explanation in your next number, in justice to a medical officer who has served the parish for eight years without a single complaint, and who, if now erring, has done so unwittingly, under the influence of motives of humanity.

I am, Sir, your obedient servant

Camden-road Villas, Sept. 1860 . JoHN HAINwORTH, F.R.C.S.

University of Edinbdrgh.-The new regulations for granting degrees by this University, proposed by the Scottish Universities Commission, will not, we understand, come into operation for this session, in consequence of their consideration by the Privy Council having been delayed till November.
PARISIAN MEDICAL INTELLIGENCE.

(FROM OUR SPECIAL CORRESPONDENT.)

A PAPER was read at the last meeting of the Academy of Sciences by M. Jobert de Lamballe, in which the progress of vascular and nervous reproduction, as observed during the cicatrization of engrafted skin, is accurately studied. The operation serving as text for this essay was undertaken for the purpose of remedying a deformity resulting from the removal of a secondary cancer. The region occupied by the unsightly cicatrix was the right eyebrow, the inner angle of the eye, and ala of the nose on the same side. In providing a flap destined to cover this unbecoming scar, the surgeon dissected off from the forehead a somewhat pear-shaped patch of skin, (the exact size requisite having previously been ascertained by measurement,) with the exception of a narrow slip, or pedicle, reserved for the conveyance of vascular supply to the flap; the whole was completely detached from the surrounding integument, and turned down upon the scar, (itself also deprived of its imperfect superstratum of cutis, ) and there secured by the interrupted suture. The engrafted slip of tissue-much in the position of a man who has purchased a practice in a new neighbourhood, with a limited introduction-to use a horticultural phrase, took kindly to its new soil, and by the eighth day the sutures were dispensed with. The temperature of the transplanted skin remained low, however, and its texture flabby and inelastic; a slight prick with a pin on its surface was not followed by bleeding, and pressure or tickling was referred to the pedicle alone. That some vascular supply did, however, reach its vessels was incontestable, for the part presented no appearance of gangrene. Day after day the same experiments were repeated; at length a little blood followed the slight puncture, and a slight sensation was perceptible in the part pricked. These signs of returning vitality steadily augmented, and by the end of the third month after the operation, the graft was deemed to possess sufficient independent vigour to shift for it self; and the little isthmus being declared unnecessary, the flap was isolated, and its cut extremity turned down towards tho inner angle of the $\mathrm{eye}$, where the scar hitherto had purposely been left uncovered. The deformity was thus completely remedied, and the cure most successful. M. Jobert, in his remarks upon the way in which the vascular and nervous relations are established between tissues thus artificially brought into contact, draws especial attention to the consecutive advance of the two functions, the one in the wake of the other; the new circulation entailing the new innervation, and the perfect development of the former being immediately followed up by a similar progress in the latter. The author also expresses it as his opinion, that the mode in which the correct sensibility of the engrafted tissue is restored after transplantation by means of its communications with the part into which it is deposited, is a proof of the unity and identity of the sensitive function all over the body.

A paper of some interest, also sent for the perusal of the Academy of Sciences, bears the following title, "Chemical Theory Explanatory of the Assimilation of Phosphate of Lime and of the Necrosis caused by Phosphorus." The following is a summary of the author's views on these subjects:-Phosphate of lime, when administered by the mouth, undergoes a first change by mingling with the saliva, which secretion holds in solution a certain amount of phosphate of soda; a second, by the contact of the phosphate of ammonia contained in the gastric juice; and a third, due to the action of the lactic acid of the mucus secreted by the stomach-each change being marked by increased solubility. In this state the salt of lime passes into the veins, where its capacity for solution is again augmented by the presence of the carbonic acid, and the venous blood passes into the lungs strongly charged with it. During the respiratory combustion, the carbonic acid being given off, and the lactic acid consumed, the phosphate of lime is alone beholden for its solution to the soluble phosphates actually present with it in the blood. If these be in small quantity, the lime is thrown down and appropriated by the osseous tissues for their reparation, a trifling amount only passing off with the urine. If, however, on the other hand, the soluble phosphates (soda and ammonia) be in excess, the lime is not precipitated, but continues in solution; little or none is distributed to the system for bone-making purposes, and all, or nearly all, is excreted 